Educators' use of commanding language to direct infants' behaviour in : Relationship to educators' qualifications and implications for language learning opportunities

Jiangbo $\mathrm{Hu} \quad$ Department of Educational Studies, Macquarie University Jane Torr Department of Educational Studies, Macquarie University Sheila Degotardi Department of Educational Studies, Macquarie University Feifei Han Department of Educational Studies, Macquarie University

Corresponding author: Jiangbo $\mathrm{Hu}$

Department of Educational Studies, Macquarie University, Sydney, Australia 2109 jiangbo.hu@mq.edu.au

Acknowledgment: This research was supported under the Australia Research Council discovery projects funding scheme: DP140101238. 


\section{Educators' use of commanding language to direct infants' behaviour: Relationship to educators' qualifications and implications for language learning opportunities}

This study investigated the manner in which 56 infant educators used language to direct the behaviour of infants (defined as children aged birth to two years), on the basis that the ways in which educators frame their commands represent an important component of young children's learning experiences. Underpinned by systemic functional linguistic theory, the study analysed the frequency and type of command produced by educators with university, diploma and certificate qualifications. Suggestive and indirect commands convey a sense of negotiation, as if the addressees' subjective opinions and thoughts are considered, while nonsuggestive and direct commands foreground the speakers' power and authority. The findings demonstrate that commands feature frequently in educators' talk to infants, with nonsuggestive and direct commands being most commonly used. Individual differences were related to the qualifications of staff. University qualified early childhood teachers used significantly fewer nonsuggestive and direct commands than did diploma and certificate qualified educators, and they were more likely to provide infants with a reason for the command. These findings have implications for the way in which learning opportunities are created by the language that educators use, and for the overall quality of infant early childhood programs.

Keywords: infants, childcare, language, commands, teacher qualifications

\section{Introduction}

The language that educators use when addressing young children is one of their most powerful instruments for establishing trusting relationships, and strong relationships are fundamental to the establishment of an effective learning environment (Hamre, Hatfield, Pianta and Jamil, 2013, Kontos and Wilcox-Herzog, 1997). It is therefore significant to 
investigate the nature of the child-addressed talk which takes place in early childhood education and care (ECEC) contexts. Research has established that the amount and characteristics of language addressed to children is related to their current and subsequent language development (Bernstein 2000, Hoff 2006, McCartney 1984, O'Brien and Bi 1995, Rowe 2012, Rudd, Cain, and Saxon 2008, Vernon-Feagans and Bratsch-Hines 2013, National Institute of Child Health and Human Development Early Child Care Research Network 2000). However, one important feature of child-directed talk, which is infrequently discussed in the early childhood literature, is the function that such talk serves in the guidance and regulation of infants' behaviour within the ECEC setting. This article aims to address that gap by examining the characteristics and prevalence of commanding language used by educators to infants, who we define as children under the age of two.

Sociolinguistic research has shown that the manner in which adults habitually use certain types of language to regulate children's behaviour varies in ways which are related to their social positioning or socioeconomic status (Bernstein 2000, Hasan 1992a, 2009, Williams 2001), as different types of meaning "are differentially accessible to different social groups" (Halliday 1978, p. 2). Given that educators working in rooms with children under 2 years of age vary in terms of their early childhood qualifications, and that previous research has suggested a relationship between educators' qualifications and their interactions with infants (Degotardi 2010, Davis and Torr 2016), it is relevant to consider the relationship between the manner in which they systematically use such language and their professional early childhood qualifications.

\section{Literature review}

The nature, purpose and effectiveness of educators' use of commanding language has been explored from a range of perspectives (Rogers, 2015). While some of this research has 
investigated school teachers' commands (Matheson and Shriver 2005), in this study we have focused on educators of children in the prior to school years. One issue that immediately arises when reviewing this literature concerns the diverse ways in which the term 'command' is defined. In some educational literature, the unmarked realisation of the speech function 'command' is the imperative mood (for example come here), yet there are many other language forms which serve to direct and regulate the behaviour of others. Bertsch, Houlihan, Lenz and Patte (2009), for example, include certain types of questions and statements in their list of 'command types'. They investigated whether the frequency and type of commands produced by educators varied according to the age of the children being addressed. Educators of three different groups of children aged two to three years, three to four years, and four to six years participated in their study. They found that educators in the two to three year old room used more indirect commands (for example those cookies are for later), compared with educators of children aged three years and older. The occurrence of educators' direct commands like come here was highest in the three to four year old children's room. Educators' 'interrogation' commands (for example how old are you), which require a verbal response, were most common in the four to six year old children's room.

Bertsch et al. (2009) suggested that the educators' greater use of direct commands with three to four year old children was a response to the children's need for more direct guidance as they made the transition from the less structured toddlers' room to the more structured pre-academic programs in the three to four year old room. The greater use of interrogation commands with the oldest pre-schoolers was attributed to their greater verbal fluency. Thus the language choices made by educators were seen as a response to children's pre-existing needs and/or abilities, rather than as an outcome of educators' beliefs about what meanings are important when regulating children's behaviour. 
Another body of research has investigated the relationship between educators' use of directiveness in their child-addressed talk and children's verbal productivity (Girolametto et al. 2000). The term "directiveness" refers to educator talk which is intended to elicit a particular verbal or nonverbal response from a child or group of children, and thus directive language may be realised by commands, questions and statements which are intended to control the child's behaviour. Some studies have suggested that educators' directive talk may inhibit language development, either because it lacks sensitivity to the child's immediate focus of interest and attention or because it inhibits children's engagement in conversations on topics of their choice (O'Brien and Bi 1995, Ogilvy 1992, Pellegrino and Scopesi 1990). It has been proposed that directiveness is more likely to occur in group childcare contexts, compared with the home environment, because educators have a greater need to manage group behaviour, implement health and safety protocols, and ensure children participate in group activities (Girolametto et al. 2000).

Girolametto, Weitzman, van Lieshout and Duff (2000) investigated whether educators' directiveness varies according to children's age (two year olds versus three to four year olds) and type of activity (play-dough versus group book reading), and whether there was a relationship between directiveness and children's verbal productivity (volubility and complexity). Five types of directiveness were investigated: response control, topic control, turn-taking control, behaviour control and conversation control. The researchers found that there was little difference in the amount of directive language addressed to the two age groups. There were differences, however, in the type of directive language during the different activities, and children's language productivity. Educators produced fewer directives during the play-dough activity, and children were more voluble and produced talk of greater complexity. Behavioural and turn-taking control were associated with less child talk. Educators' use of conversation control, which was defined as 'all open-ended Wh- 
questions, clarification questions that repair breakdowns, and yes/no questions that promote conversation without directing behaviour' (Girolametto et al p. 1113), was associated with children's greater language productivity. It may be argued that the characteristics referred to as 'conversation control' are less a form of control and more a feature of conversational engagement.

Much of the research on educators' use of language to command, direct and regulate children's verbal and non-verbal behaviour has focused on environmental features such as the ages of the children, the type of activity, and other environmental influences. Little research has explored whether variations in this type of language may relate to attributes of the educators themselves. The present study draws on insights from educational linguistics (Bernstein 2000, Hasan and Cloran 1990, Halliday 1978, 1993, Hasan 1992a, 1992b, 2009, Williams 2001), underpinned by systemic functional linguistic theory (Halliday and Matthiessen 2004, Halliday 1994), to investigate educators' infant-addressed commands in terms of their potential to promote infants' language development and learning more generally.

\section{Semantic framework informing the present study}

This study is informed by Hasan's (1992a, 2009) analysis of the manner in which mothers use language to control their three to four year old children's behaviour during everyday interactions in the home. The mothers differed according to their educational qualifications: half the mothers had a university degree and/or professional training (referred to as High Autonomy Professionals or HAPs), and half the mothers had a high school certificate as their highest educational qualification (referred to as Low Autonomy Professionals or LAPs). Hasan sought to determine whether there were systematic and significant differences between the two groups of mothers in the meanings they considered relevant when regulating their 
children's verbal and non-verbal behaviour. Rather than simply counting the mothers' speech functions, words or grammatical structures in isolation, Hasan developed a "semantic network" which captured the patterns of meaning (the semantic stratum) which were "realised" or expressed in the words and structures produced by the mothers.

Hasan (1992a) made a basic distinction between two mutually exclusive semantic features in the context of commands. A command could be either direct (for example take your shoes off first) or indirect (for example we'll take your shoes off first). Cutting across this dimension is another mutually exclusive option: a command may be either suggestive (for example let's take your shoes off first) or non-suggestive (for example you have to take your shoes off first). Hasan specified each semantic feature in terms of its distinctive lexicogrammatical realisation. For example, commands with the semantic feature suggestive are realised through the choice of the subject let's or we, while commands with the semantic feature direct are realised through the choice of imperative mood. Hasan (1992a) provides a complete list of the semantic options and their lexicogrammatical realisations.

Hasan (1992a and 2009) found statistically significant differences between the two groups of mothers in their use of language in the regulation of their children's behaviour. The high autonomy professional (HAP) mothers were more likely to control their children's behaviour using indirect commands; for example shall we clear away the blocks now and could you clear away the blocks please. The low autonomy professional (LAP) mothers, on the other hand, were more likely to issue direct commands, such as you have to put away the blocks and put the blocks away now.

Another significant difference between the two groups of mothers was their use of reasoning to supplement their commands (Hasan 1992a, 2009). The HAP mothers were more likely than the LAP mothers to provide reasons for their commands (for example don't keep bouncing around or you'll spill it) and their reasons were more elaborated compared with the 
LAP mothers (for example let's not touch that, it's Rebecca's doll and if you break her she'll be very upset). The nature of the rationale underpinning the mother's reasoning also differed (Hasan 1992b). The HAP mothers' reasons were more likely to be logical and based on the irrefutable laws of nature and cause-and-effect, for example, don't touch the stove, it's hot, whereas the LAP mothers' reasons were more likely to be located in the nature of the social roles expected of parents and children (for example, don't touch the stove because Mummy said no).

The relationship between the social positioning of the mothers and the manner in which they use language to control their children's behaviour has implications for children's subsequent language and literacy development, their learning more generally, and their potential for academic success:

When children learn language, they are not simply engaging in one kind of learning among many; rather, they are learning the foundation of learning itself. The distinctive characteristic of human learning is that it is a process of making meaning a semiotic process; and the prototypical form of human semiotic is language. Hence the ontogenesis of language is at the same time the ontogenesis of learning. (Halliday, 1993, p. 93).

When mothers use indirect commands, they create a conversational tone through which their authority over their child is made less visible and overt. This subtly suggests a recognition of, and respect for, their child as a separate individual with mental processes which are not accessible to others without verbal explication. Interestingly, while children's compliance was not a focus of Hasan's research, she observed that the children of HAP mothers were more compliant than were the children of LAP mothers, who tended to demonstrate more defiance in response to their mothers' commands. Kuczynski and Kochanska (1990), who were not researching within a message semantics framework, also observed a positive 
relationship between parents' use of indirect commands with their toddler children, and these children's greater compliance when they reached 5 years of age.

Furthermore, according to Hasan (1992a, 2009), a command supplemented with a reason requires greater verbal specificity on the part of the mother, as she makes explicit her awareness of her child as an independent individual who requires an explanation for, and can make a judgment regarding, the behaviours expected of her or him. The nature of the reasons provided by the mothers for their commands also has implications for children's current and future learning about 'scientific ways of knowing' and social relationships. Reasoning grounded in the rules of logic and cause and effect in the natural world are valued in academic discourses, particularly in science and mathematics (Hasan 1992b, van Kleeck 2014). When adults use such reasoning to control children's behaviour, children gain experience in discourses which are valued in academic contexts. Logical reasoning is more difficult for children to challenge and refute compared with social reasoning, which more visibly and explicitly foregrounds parental authority and control.

Hasan's research has demonstrated how parents from different socioeconomic backgrounds vary in terms of the language they use to control children's behaviour. Research within other paradigms has also demonstrated a relationship between maternal education, socioeceonomic status and language input to children, with implications for children's subsequent language and literacy development (Hart and Risley 1995, Hoff 2003, Heath 1982, 1983). This raises questions regarding the professional qualifications of long day care staff. Lead teachers working in preschools, primary and secondary schools in Australia are required to have at least a university degree and specialist professional training. This is unlike the situation pertaining in rooms for children under two years, where lead educators may hold a certificate, diploma, or university qualification. Hasan's research raises the possibility, to be investigated in the present study, that within the long day care centre, the educational and 
professional backgrounds of staff may be related to the manner in which they systematically interact with infants and toddlers, with implications for children's long term language and literacy development.

\section{Research questions}

This study aims to investigate the nature of educators' use of commanding language in the direction of infants' behaviours, and whether educators' qualifications are associated with their language use. Specifically, the study will address the following questions:

(1) To what extent do infant educators use commands and provide reasons to supplement their commands when interacting with infants during play?

(2) Are there differences in the proportion of total commands and types of commands produced by educators with different qualification levels?

(3) Are there differences in the proportions of total reasons and types of reasons produced by educators with different qualification levels to supplement their commands during play?

\section{Methodology}

\section{Participants}

The participants in this study were 56 early childhood educators working in programs for infants (that is, children under two years of age) from 56 long day care centres in Sydney, Australia. The term 'long day care centres' refers to early childhood education and care services that typically cater for children aged from 6 weeks to 5 years. Long day care centres are open for minimum of eight hours per day, 48 weeks per year. This study was undertaken in long day care centres because in the Australian context, it is long day care centres rather than preschool services who cater for infants, and there is a lack of empirical research on the 
language environment experienced by infants in long day care. The participants were recruited to participate in a large-scale research project investigating the language environment of non-parental group care infant programs. An initial email was sent to 89 ECEC centres, including not-for-profit and private centres. The initial response rate was $66 \%$, generating 59 centres indicating a willingness to participate. Due to scheduling and technical difficulties with the recording equipment, two centres had to be excluded from the analysis. A further centre was excluded when it was noted that the room included a number of children over the age of two. Our final sample size was therefore 56 centres, 34 of which were not-for profit, 18 were private, and 4 were work-based centres.

Each centre director identified one focus educator who was employed on a permanent basis in the infant room, and who was willing to participate in the study. The participants, all female, varied in terms of their early childhood qualification. There are three levels of early childhood qualification in Australia ECEC centres: certificate-qualified educators $(n=18)$ have completed a vocational qualification equivalent to six months of full-time study; diploma-qualified educators have completed a vocational diploma $(n=25)$; universityqualified early childhood teachers have completed a three or four year university qualification in early childhood teaching $(n=13)$.

\section{Data collection}

The ethical aspects of the research were approved by the [university] Human Ethics Research Committee. Prior to data collection, we obtained written consent from the focus educators, all the other educators, and the parents of the infants in the room. The participants were informed that they had the right to opt out of further participation at any time during the data collection period. 
An initial visit was scheduled by an experienced research assistant (RA) to gather the focus educators' demographic information, including their age group, early childhood qualification, years of ECEC experience, and years of experience working with infants. During this visit, the RA also familiarised herself with the room layout and daily schedule of the focus educators in order to plan the video-recordings. The RA video-recorded the focus educators during their typical daily activities for approximately three hours filmed over two days. Each educator also wore a blue-tooth microphone to capture high quality audio recordings of their spoken language.

\section{Data selection}

The focus educators participated in a range of activities during the three hours of videorecording, including reading books, singing, preparing and serving meals and snacks, carrying out personal care (e.g., dressing, hand washing, settling baby for sleeping, and nappy changing), organizing and directing art experiences and cooking activities, and playing with children. For this study, we focused on educators' use of commanding language during periods of free play that could include a variety of activities, such sandpit play, water play, block construction, climbing on equipment and play dough activity. Two criteria informed the selection of video footage for analyses: first, the focus educator needed to be present during the entire 20-minute educator guided, but freely chosen play activities from beginning to the end, and secondly, the focus educator needed to be actively interacting with the children during the 20 minutes. The first 20 minutes in the video-recording of individual cases that fit these criteria was selected for analysis.

\section{Coding scheme}

\section{Commands}


The 56 20-minute samples were transcribed verbatim and any talk between educators was excluded from analysis, as our study was concerned only with the focus educators' infantaddressed talk. The transcripts were then separated into 'messages' (approximately equivalent to a clause), defined as 'the smallest semantic unit which is capable of realising an element in the structure of a text' (Hasan 1996, p.117). Each message which functioned to direct or regulate infants' verbal or non-verbal behaviours was coded as a command. Types of command

Each message coded as a command was then further coded according to command type, using the scheme presented in Table 1, based on Hasan (1992a, 2009).

Table 1. Types of command

(Insert Table 1 here)

\section{Reasoning}

Each command was further coded according to whether it was supplemented with a reason, and if so, the message was considered as a reasoning command. Each reasoning command was then further analysed regarding what type of reason was provided. Hasan (1992b) categorised reasoning into two mutually exclusive types: logical and social. Logical reasoning is grounded in the laws of nature, for example the glass will break if you drop it on the path. Social reasoning, on the other hand, is grounded in relationships in the social world, for example share with your friends so everyone gets a turn.

\section{Inter-coder reliability}

A second coder independently coded 11 randomly selected transcripts (approximately $20 \%$ of the total transcripts). The inter-coder reliability was calculated and shown to be high. The Cohen's kappa was .97 for whether the message was a command or not; .98 for the type of 
command; .88 for whether a command was followed by a reason; and .96 for the type of reason.

\section{Measures}

The total number of infant-addressed messages in the 20-minutes of footage varied widely between the 56 educators. Therefore, instead of using the raw counts, we calculated the proportions as follows:

- Proportions of total commands and types of command were calculated by dividing the total number of commands and the number of each type of command by the number of infant-addressed messages.

- Proportions of total reasons and types of reason were calculated by dividing the total reasoning commands and the types of reasons by the total number of commands.

\section{Data analysis}

In order to answer research question one, we conducted two repeated ANOVAs and post-hoc analyses. To answer research question two and three, we performed two separate multivariate analyses of variance (MANOVAs) using qualifications as independent variables, using the proportions of total commands and types of command as one set of dependent variables and the proportions of total reasoning commands and types of reason as the other set of dependent variables. Because there were three categories of qualifications, we also conducted post-hoc analysis following MANOVAs. The data analyses were performed in IBM SPSS 21.

\section{Results}

The extent to which infant educators used commands and provided reasons to supplement their commands when interacting with infants 
Table 2 demonstrates that approximately one third $(M=33.37 \%, S D=7.76 \%)$ of the educators' total infant-addressed talk was in the form of a command. Among the four types of command, the proportion of commands differed dramatically, with direct \& nonsuggestive commands (for example come here) being the most commonly used form, comprising $60.21 \%$ percentage of all commands, and indirect \& nonsuggestive commands (for example let's go out) being the least common form of command, accounting for only $5.40 \%$ of the total commands. On average, fewer than $15 \%(M=13.98 \%, S D=9.83 \%)$ of the educators' commands were supplemented with a reason. The educators also varied greatly in terms of the nature of the reasoning used to supplement the command (logic: $M=5.06, S D=4.59 \%$; social: $M=8.92, S D=7.11 \%)$.

Table 2. Descriptive statistics

(Insert Table 2 here)

A repeated ANOVA and post-hoc analysis were conducted to determine whether the frequency with which the educators used the four discrete types of commands differed. The results showed a significant difference in the proportions of the four types of command produced by the educators, $F(1,53)=165.60, p<.01$, partial $\eta^{2}=.75$. Bonferroni post-hoc analysis showed that among the four types of command, the highest proportion of commands used by the educators was the direct \& nonsuggestive type of command $(M=20.68 \%, S D=$ $8.68 \%)$ followed by the indirect \& suggestive type of command $(M=8.46 \%, S D=3.57 \%)$. There was no significant difference in terms of the proportions of direct $\&$ suggestive $(M=$ $2.50 \%, S D=1.90 \%)$ and indirect $\&$ nonsuggestive commands $(M=1.73 \%, S D=1.09 \%)$ produced by the educators. 
When comparing the types of reasoning provided by the educators, the repeated ANOVA revealed a significant difference in the types of reasons they provided, $F(1,55)=$ $17.87, p<.01$, partial $\eta^{2}=.25$. Educators justified their commands with a significantly higher proportion of social reasons $(M=8.92 \%, S D=7.11 \%)$ than logical reasons $(M=5.06 \%, S D$ $=4.59 \%$.

\section{Relationships between educators' use of commands and their qualification level.}

The MANOVA which examined the effect of qualifications on the use of commands showed that the multivariate effect was significant for levels of qualification, Wilks's $\lambda=.64$, $F(2,53)=3.10, p<.01$, partial $\eta^{2}=.20$. The univariate analyses indicated that, in relation to their qualifications, the focus educators differed significantly in terms of the proportion of total commands they produced $F(2,53)=10.62, p<.01$, partial $\eta^{2}=.29$; and the proportion of direct \& nonsuggestive commands they produced $F(2,53)=4.56, p<.05$, partial $\eta^{2}=.15$. Post-hoc comparisons showed that certificate-qualified educators produced the highest proportion of total commands $(M=38.30 \%, S D=7.46 \%)$, followed by diploma-qualified educators $(M=33.10 \%, S D=5.62 \%)$ and university-qualified educators $(M=27.10 \%, S D$ $=7.42 \%)$. Certificate-qualified educators also produced a significantly higher proportion of direct \& nonsuggestive commands $(M=24.30 \%, S D=9.96 \%)$ compared with universityqualified educators $(M=15.30 \%, S D=7.65 \%)$. No significant differences were found in the proportions of the other three types of command (direct \& suggestive: $F(2,53)=0.31, p$ $=.74$, partial $\eta^{2}=.01$; indirect \& suggestive: $F(2,53)=1.32, p=.28$, partial $\eta^{2}=.05$; indirect $\&$ nonsuggestive $F(2,53)=0.07, p=.93$, partial $\left.\eta^{2}=.00\right)$.

\section{Relationships between educators' use of reasons and their qualification level.}

The MANOVA which examined the effect of qualifications on the extent to which educators supplemented their commands with a reason demonstrated a significant 
multivariate effect; Wilks's $\lambda=.51, F(2,53)=10.47, p<.01$, partial $\eta^{2}=.29$. The univariate analyses found that the focus educators differed significantly in terms of the proportion of total reasoning commands, $F(2,53)=24.16, p<.01$, partial $\eta^{2}=.48$; the proportion of their commands which were justified with logical reasons, $F(2,53)=6.57, p<.01$, partial $\eta^{2}=$ .20 ; and the proportion of their commands which were justified with social reasons, $F(2,53)$ $=21.61, p<.01$, partial $\eta^{2}=.45$.

In terms of the total proportion of reasoning commands, post-hoc analysis showed that university-qualified educators provided a higher proportion of reasons $(M=26.02 \%, S D=$ $1.09 \%)$ compared with diploma $(M=11.48 \%, S D=6.52 \%)$ and certificate-qualified educators $(M=8.74 \%, S D=4.39 \%)$. There was no significant difference between diploma and certificate-qualified educators in terms of the proportion of reasoning commands they produced. A similar pattern of results was found for the proportion of different types of reasons provided by the educators. University-qualified educators used a significantly higher proportion of both logical and social reasons (logical: $M=8.58 \%, S D=6.44 \%$; social: $M=$ $17.44 \%, S D=8.10 \%$ ) than did diploma and certificate-qualified educators (logical: $M=$ $4.57 \%, S D=3.50 \%$; social: $M=6.91 \%, S D=4.53 \%$; logical: $M=3.19 \%, S D=2.83 \%$; social: $M=5.55 \%, S D=3.87 \%$ respectively). Again, the difference between diplomaqualified and certificate-qualified educators was not significant.

In summary, the results demonstrate that commands feature strongly in the talk addressed to infants during play in long day care centres, with direct $\&$ nonsuggestive commands being the most prevalent. Educators with different qualifications varied significantly in terms of the amount and the types of command they used. When addressing infants during play, the university-qualified educators employed fewer commands overall, and fewer direct \& nonsuggestive commands, compared with less highly qualified educators. 
Furthermore university-qualified educators tended to supplement their commands with reasons more frequently than did certificate or diploma-qualified educators.

\section{Discussion}

This study focused on the language choices educators spontaneously make when guiding and regulating the verbal and non-verbal behaviour of infants in long day care centres. Previous research suggests that such child-addressed language has implications for children's language development and familiarity with the language registers which are valued in formal school contexts (Bernstein 2000; Girolametto, Weitzman, van Lieshout \& Duff, 2000; Hasan 2009, McCartney 1984; van Kleeck 2014; Williams, 2001). Research on children's language experiences in preschools demonstrates a correlation between the educators' language use and the children's future language and literacy abilities (Hamre, 2014). For example, teachers' use of sophisticated and unusual vocabulary was related to children's words comprehension and recognition skills in their kindergarten and early school years (Dickinson and Porche, 2011). By employing a semantics-based approach to the analysis of commands (Hasan 1992, 1996, 2009), underpinned by systemic functional linguistic theory (Halliday 1994; Halliday \& Matthiessen 2004:), it has been possible to analyse the different ways that educators use language to direct infants' behaviour and to interpret these differences in terms of a language-based theory of learning (Halliday, 1993).

In general terms, the speech function 'command' refers to language which is involved in the negotiation of "goods and services" (Halliday 1994, Halliday and Matthiessen 2004), and thus the speech functional options available in response to a command are either to comply or refuse to comply. The results of this study show that educators' commands comprise approximately one third of their infant-addressed talk during play. As educators' commands serve an important role in guiding infants to follow daily routines, join in group 
activities, and learn new physical skills such as hand-washing, it is perhaps not surprising to find such a high proportion of commands in their infant-addressed talk.

Yet certain types of educators' commands can provide children with language learning opportunities. The different ways in which educators use language to issue their commands are relevant to the quality of the language learning environment created in long day care centres. In this study, the most frequently produced educators' commands were the direct and non-suggestive type, which as the name suggests, make visible and explicit the authority of the educator over the infant, whose options in response are to comply or not. In one example, an educator guiding an infant during an art activity used direct and nonsuggestive commands to control the infant's experience, saying 'some (printing) here [indicating where on the page the child should print], that's it, finished'. The less frequently used types of command were indirect, or suggestive, or had both features, for example, 'How about we leave the bike outside of the bathroom Oliver?' These command types served to render less visible the authority of the educator, creating a more conversational tone and subtly suggesting that the infant addressee has some discretion over whether or not to comply.

It could be argued that the prevalence of commanding language with its focus on the negotiation of goods and services may restrict infants' experience of the more diverse and complex types of language associated with episodes of joint attention, where the focus is on the exchange of information and generation of new knowledge and understandings, rather than on "getting things done". This may be true when commands are direct and not supported with a reason for the command, as was the case with a majority of the educators' commands. Yet when educators supplement their infant-addressed commands with a reason, they are foregrounding the importance of using language as an instrument to argue a position and 
provide a justification for the command. By articulating the rationale behind the command, the educator is demonstrating respect for the child's subjectivity and highlighting the fact that the subjectivity of others cannot simply be assumed, but must be accessed through explicit verbal explanation. The infant is thus gaining early experience in the types of discourse which are fundamental to academic success.

Hamre (2014) reviewed recent research relating to educator-child interactions in preschools and pointed out that many children in early childhood settings do not have the opportunity to experience high-quality interactions involving higher order thinking (e.g. logical thinking). When educators justify their commands with reasons, they are providing children with an experience of the use of language to express cause and effect relations in their own lives. The addressee's compliance with the command is recontextualised as if it were a consequence of the addressee's decision based on evidence, rather than obedience to the authority of a more powerful entity. Furthermore, the infant has the opportunity to experience and become familiar with the language of explanation and argumentation, both of which are valued genres in academic discourses. The finding that educators employed more social reasoning than logical reasoning may relate to the fact that children's social behaviour is foregrounded in a group care setting. Research shows that the situational context in which adult-child interactions occur is related to type of reasoning talk produced. For example, In the regulatory context where children's behaviours are addressed, social reasoning is more frequently used than logical reasoning (Hu \& Torr, 2016).

Perhaps the most powerful finding of this research is the relationship between the professional qualifications of the educators and the meanings they consider relevant when using language to direct children's behaviour. University-qualified educators used significantly fewer commands in their interactions with infants, and their commands were more likely to be of the indirect \& suggestive type and supplemented with reasons. No 
significant differences in the use of language to control children's behaviour were found between diploma-qualified and certificate-qualified educators, although certificate-qualified educators did use the highest proportion of direct \& non-suggestive commands among the three groups.

While the relationship between educator qualifications and child outcomes is complex and multifaceted (Fukkink and Lont 2007, Howes 1997), this study indicates that educators' level of early childhood qualification is systematically related to the manner in which they habitually interact with infants during everyday interactions. By analysing the language patterns of educators with different levels of early childhood qualification, we have demonstrated that educators with a university qualification interact in ways which have been shown to support infants' language development. This finding is in line with other research demonstrating that university-qualified educators tend to use more language-promoting strategies, such as using a variety of labels and extended talk, compared with less qualified educators during snack time in long day care centres (Degotardi et al. 2016). Children under 2 years are at a critical stage in their language development, and both the quantity and qualities of the language addressed to them is related to their current and future language development, with implications for their emergent literacy.

\section{Limitations and avenues for future research}

This study was subject to a number of limitations. The data were gathered in the form of 'snapshots' taken during three visits to the long day care centres over a relatively short period of time. The centres were visited at different times of the year. Some centres were visited early in the year when infants were settling in to their new environment, while some centres were observed later in the year when infants were more settled and likely to engage more freely in various types of play. The timing of visits may thus have played an indirect role in shaping the educators' infant-addressed talk. Undertaking more observations from multiple 
visits throughout a longer period of time may allow us to determine whether educators' use of commanding language is consistent across time. Another limitation is the fact that this study has focused only on the educators' commands, without simultaneously analysing the children's verbal and non-verbal responses to different types of commands across contexts and times of the day. Further investigation combining children's responses may provide more evidence about how educators' language use could influence children's language development.

There is still much to learn about the language environment in long day care centres, particularly for children under 2 years of age, and the manner in which educators use language to guide and control children's behaviour. For example, anecdotal observations suggest that the social and cultural background of educators may influence the language they use in controlling children's behaviour. As Bernstein (2000) points out, the regulatory context shapes, and is shaped by, the rules, moral values and social identities of communities, and is thus an important domain for further investigation.

Note: We gratefully thank the educators and infants who were willing to participate in this study and generously allowed our RAs to observe and film their practices.

\section{Reference}

Bernstein, B. B. 2000. Pedagogy, Symbolic Control and Identity: Theory, Research Critique. Rev ed. Lanham, Maryland: Rowman \& Littlefield Publishers.

Bertsch, K. M, D Houlihan, M. A Lenz, and C. A Pate. 2009. "Teachers' Commands and Their Role in Preschool Classrooms." Electronic Journal of Research in Educational Psychology 17 (7):133-162.

Davis, B, and J Torr. 2016. "Educators' Use of Questioning as a Pedagogical Strategy in Long Day Care Nurseries." Early Years: An International Research Journal 36 (1):97-111. doi:10.1080/09575146.2015.1087974

Degotardi, S. 2010. "High-quality Interactions with Infants: Relationships with Earlychildhood Practitioners' Interpretations and Qualification Levels in Play and Routine Contexts." International Journal of Early Years Education 18 (1):27-41. doi: http://dx.doi.org/10.1080/09669761003661253

Degotardi, S, J Torr, and N Nguyen. 2016. "Infant-toddler Educators' Language Support Practices during Snack-time." Australasian Journal of Early Childhood 41(4): 52-62. http://search.informit.com.au/documentSummary; $\mathrm{dn}=619097547250550 ;$;es=IELHSS 
Dickinson. D. K., and M V Porche. 2011. "Relation between Language Experiences in Preschool Classrooms and Children's Kindergarten and Fourth-grade Language and Reading Abilities. Child Development, 82(3), 870-886. doi: 10.1111/j.14678624.2011.01576.x

Fukkink, R. G, and A Lont. 2007. "Does Training Matter? A Meta-analysis and Review of Caregiver Training Studies." Early Childhood Research Quarterly 22:294-311. doi: 10.1016/j.ecresq.2007.04.005.

Girolametto, L, R Weitzman, R Van Lieshout, and D Duff. 2000. "Directiveness in Teachers' Language Input to Toddlers and Pre-schoolers in Day Care." Journal of Speech, Language, and Hearing Research 43 (5):1101-1114. doi: 10.1044/jslhr.4305.1101.

Halliday, M. A. K. 1978. Language as Social Semiotic: the Social Interpretation of Languge and Meaning. London: Edward Arnold.

Halliday, M. A. K. 1993. "Towards a Language-based Theory of Learning." Linguistics and Education 5 (2):93-116. doi: 10.1016/0898-5898(93)90026-7.

Halliday, M. A. K. 1994. An Introduction to Functional Grammar. 2nd ed. London: Arnold.

Halliday, M. A. K, and C Matthiessen. 2004. An Introduction to Functional Grammar. 3rd ed. London: Arnold.

Hamre, B. K. 2014. "Teachers' Daily Interactions with Children, and Essential Ingredient in Effective early Childhood Program." Child Development Perspectives, 8(4), 223-230. doi: 10.1111/cdep. 12090

Hamre, B, B Hatfield, R Pianta, and F, Jamil. 2013. Evidence for General and DomainSpecific Elements of Teacher-Child Interactions: Associations With Preschool Children's Development. Child Development, 85(3): 1257-1274 doi:

10.1111/cdev.12184

Hart, B, and T Risley. 1995. Meaningful Differences in the Everday Experience of Young American Children. Baltimore: Paul H. Brookes Publishing.

Hasan, R. 1992a. "Meaning in Sociolinguistic Theory." In Sociolinguistics today: International Perspectives, edited by K Bolton and H Kwok, 80-119. London: Routledge.

Hasan, R. 1992b. "Rationality in Everyday Talk: From Process to System." In Directions in Corpus Linguistics. Proceedings of Nobel Symposium 82 Stockholm, edited by $\mathbf{J}$ Svartik, 257-307. Berlin: Walter de Gruyter.

Hasan, R. 1996. "Semantic Networks: A tool for the Analysis of Meaning." In Ways of Syaing Ways of Meaning (Selected Papers of Ruqaiya Hasan), edited by C Cloran, D Butt and G Williams, 104-131. London: Cassell.

Hasan, R. 2009. "Contexts for Meaning." In Semantic Variation: Meaning in Society and Sociolinguistics (Collected Works of Ruqaiya Hasan), edited by J Webster, 104-131. Sheffield, UK: Equinox Publishing.

Hasan, R, and C Cloran. 1990. "A Sociolinguistic Study of Everyday Talk between Mothers and Children." In Learning, Keeping and Using Language, edited by M. A. K Halliday, G Gibbons and H Nicholas, 67-100. Amsterdam: John benjamins.

Heath, S. B. 1982. "What No Bedtime Story Means: Narrative Skills at Home and School." Language in Society 11:49-76. doi: 10.1017/S0047404500009039.

Heath, S. B. 1983. Wyas with Words: Language, Life and Work in Communities and Classrooms. Cambrige: Cambrige University Press.

Hoff, E. 2003. "The Specificity of Enviornmental Influence: Socioeconomic Status Affects Early vocabulray Development via Maternal Speech." Children Development 74:1368-1378.

Hoff, E. 2006. "How Social Contexts Support and Shape Language Development." Developmental Review 26:55-58. 
Holliday, M. A. K. 1978. Language as Social Semiotic: The Social Interpretation of Language and Meaning. London: Edward Arnold.

Howes, C. 1997. "Children's Experiences in Center-based Child Care as a Function of Teaching Background and Adult-child Ratio." Merrill-Palmer Quarterly 43 (3):404425.

$\mathrm{Hu}$, J, and Torr, J. 2016. "A Study of Reasonging Talk between Australian Chinese Mothers and Their Preschool Children: What Messages are Mothers Sending?" Journal of Language, Identity and Education 15(3): 180-193. doi: 10.1080/15348458.2016.1169801

Kuczynski, L, and G Kochanska. 1990. "Development of Children's Noncompliance Strategies from Toddlerhood to Age 5." Developmental Psychology 26:477-491.

Kontos, S, and Wilcox-Herzog, A. 1997. "Teachers' Interactions with Children: Why are They so Tmportant? Research In Review." Yong Children 52(2): 4-12.

Matheson, A. S, and M. D Shriver. 2005. "Training Teachers to Give Effective Commands: Effect on Student Compliance and Academic Behaviour." School Psychology Review 34 (2):202-219.

McCartney, K. 1984. "Effect of Quality of Day Care Enviornment on Children's Language Development." Developmental Psychology 20 (2):244-260.

National Institute of Child Health and Human Development Early Child Care Research Network, (NICHD ECCRN). 2000. "The Relation of Child Care to Cognitive and Language Development." Child Development 71 (4):960-980. doi: 10.1111/14678624.00202.

O'Brien, M, and X Bi. 1995. "Language Learning in Context: Teacher and Toddler Speech in Three Classrom Play Areas." Topics in Early Childhood Speical Education 15:148163. doi: 10.1177/027112149501500202.

Ogilvy, C. M. 1992. "How Might Psychological Research Findings be Applied to Increase the Effectiveness of Nurseries as Learning Contexts?" Early Child Development and Care 81:65-75.

Pellegrino, M. L. M, and A Scopesi. 1990. "Stucture and Function of Baby Talk in a Daycare Centre." Journal of Child Language 17:101-113.

Rogers, B. 2015. Classroom behaviour: A practical guide to effective teaching, behaviour management and colleague support. London: Sage.

Rowe, M. L. 2012. "A Longitudinal Investigation of the Role of Quantity and Quality of Child-directed Speech in Vocabulary Development." Child Development 83 (5):1762-1774. doi: 10.1111/j.1467-8624.212.1805.x.

Rudd, L; C, D. W Cain, and T. F Saxon. 2008. "Does Improving Joint Attention in Lowquality Child-care Enhance Language Development?" Early Child Development and Care 178 (3):315-338. doi: 10.1080/03004430701536582.

van Kleeck, A. 2014. "Distinguishing between Casual Talk and Academic Talk Beginning in the Preschool Years: An Important Consideration for Speech-language Pathologists." American Journal of Speech-Language Pathology 23 (4):724-741. doi: 10.1044/2014_AJSLP-14-0032.

Vernon-Feagans, L, and M. E Bratsch-Hines. 2013. "Caregiver-child Verbal Interactions in Child Care: A Buffer Against Poor Language Outcomes When Maternal Language Input Is Less." Early Childhood Research Quarterly 28:858-873. doi: http://dx.doi.org/10.1016/j.ecresq.2013.08.002.

Williams, G. 2001. "Literacy Pedagogy Prior to Schooling: Relations between Social Positioning and Semantic Variation." In Toward a Sociology of Pedagogy: The Contribution of Basil Bernstein to Research, edited by A Morais, I Neves, B Davies and H Baillie, 17-45. New York: Peter Lang. 